\title{
NONLINEAR CONTRACTIONS AND FIXED POINTS IN COMPLETE DISLOCATED AND b-DISLOCATED METRIC SPACES
}

\author{
Elida Hoxha ${ }^{1}$, Kastriot Zoto ${ }^{2}$ and Panda Sumati Kumari ${ }^{3}$
}

\begin{abstract}
In this paper, we continue the study of complete dislocated and b-dislocated metric spaces and established some common fixed point theorems for one and two mappings. Our results generalizes and extend some existing results in the literature in a class effectively larger such as b-dislocated metric spaces, where the self distance for a point may not be equal to zero.
\end{abstract}

\section{INTRODUCTION}

The concept of $b$-metric space was introduced by Bakhtin [4] and extensively used by Czerwik in [10]. After that, several interesting results about the existence of a fixed point for single-valued and multi-valued operators in $b$-metric spaces have been obtained. Recently there are a number of generalizations of metric space. Some of them are the notions of dislocated metric spaces and $b$-dislocated metric spaces where the distance of a point in the self may not be zero. These spaces was introduced and studied by Hitzler and Seda [5], Nawab Hussain et.al [7]. Also in [7] are presented some topological aspects and properties of $b$-dislocated metrics. Subsequently, several authors have studied the problem of existence and uniqueness of a fixed point for single-valued and set-valued mappings and different types of contractions in these spaces.

The purpose of this paper is to unify and generalize some recent results in the setting of dislocated and $b$-dislocated metric spaces using a class of continuous functions $G_{4}$.

\section{Preliminaries}

Definition 2.1 [6]. Let $X$ be a nonempty set and a mapping $d_{l}: X \times X \rightarrow[0, \infty)$ is called a dislocated metric (or simply $d_{l}$-metric) if the following conditions hold for any $x, y, z \in X:$
i. If $d_{l}(x, y)=0$, then $x=y$
ii. $\quad d_{l}(x, y)=d_{l}(y, x)$

2010 Mathematics Subject Classification. Primary: 47H10 Secondary: 55M20

Key words and phrases. dislocated metric, $b$-dislocated metric, fixed point, contraction. 
iii. $\quad d_{l}(x, y) \leq d_{l}(x, z)+d_{l}(z, y)$

The pair $\left(X, d_{l}\right)$ is called a dislocated metric space (or $d$-metric space for short). Note that when $x=y, d_{l}(x, y)$ may not be 0 .

Example 2.2. If $X=R$, then $d(x, y)=|x|+|y|$ defines a dislocated metric on $X$.

Definition 2.3 [6]. A sequence $\left(x_{n}\right)$ in $d_{l}$-metric space $\left(X, d_{l}\right)$ is called:

(1) a Cauchy sequence if, for given $\varepsilon>0$, there exists $n_{0} \in N$ such that for all $m, n \geq n_{0}$, we have $d_{l}\left(x_{m}, x_{n}\right)<\varepsilon$ or $\lim _{n, m \rightarrow \infty} d_{l}\left(x_{n}, x_{m}\right)=0$,

(2) convergent with respect to $d_{l}$ if there exists $x \in X$ such that $d_{l}\left(x_{n}, x\right) \rightarrow 0$ as $n \rightarrow \infty$. In this case, $x$ is called the limit of $\left(x_{n}\right)$ and we write $x_{n} \rightarrow x$.

A $d_{l}$-metric space $X$ is called complete if every Cauchy sequence in $X$ converges to a point in $X$.

Definition 2.4[8]. Let $X$ be a nonempty set and a mapping $b_{d}: X \times X \rightarrow[0, \infty)$ is called a $b$-dislocated metric (or simply $b_{d}$-dislocated metric) if the following conditions hold for any $x, y, z \in X$ and $s \geq 1$ :

a. If $b_{d}(x, y)=0$, then $x=y$,

b. $b_{d}(x, y)=b_{d}(y, x)$,

c. $b_{d}(x, y) \leq s\left[b_{d}(x, z)+b_{d}(z, y)\right]$.

The pair $\left(X, b_{d}\right)$ is called a $b$-dislocated metric space. And the class of $b$-dislocated metric space is larger than that of dislocated metric spaces, since a $b$-dislocated metric is a dislocated metric when $s=1$.

In [8] was showed that each $b_{d}$-metric on $X$ generates a topology $\tau_{b_{d}}$ whose base is the family of open $b_{d}$-balls $B_{b_{d}}(x, \varepsilon)=\left\{y \in X: b_{d}(x, y)<\varepsilon\right\}$

Also in [8] are presented some topological properties of $b_{d}$-metric spaces

Definition 2.5. Let $\left(X, b_{d}\right)$ be a $b_{d}$-metric space, and $\left(x_{n}\right)$ be a sequence of points in $X$. A point $x \in X$ is said to be the limit of the sequence $\left(x_{n}\right)$ if $\lim _{n \rightarrow \infty} b_{d}\left(x_{n}, x\right)=0$ and we say that the sequence $\left(x_{n}\right)$ is $b_{d}$-convergent to $x$ and denote it by $x_{n} \rightarrow x$ as $n \rightarrow \infty$.

The limit of a $b_{d}$-convergent sequence in a $b_{d}$-metric space is unique [8, Proposition 1.27]. 
Definition 2.6. A sequence $\left(x_{n}\right)$ in a $b_{d}$-metric space $\left(X, b_{d}\right)$ is called a $b_{d}$-Cauchy sequence iff, given $\varepsilon>0$, there exists $n_{0} \in N$ such that for all $n, m>n_{0}$, we have $b_{d}\left(x_{n}, x_{m}\right)<\varepsilon$ or $\lim _{n, m \rightarrow \infty} b_{d}\left(x_{n}, x_{m}\right)=0$. Every $b_{d}$-convergent sequence in a $b_{d}$-metric space is a $b_{d}$-Cauchy sequence.

Remark 2.7. The sequence $\left(x_{n}\right)$ in a $b_{d}$-metric space $\left(X, b_{d}\right)$ is called a $b_{d}$-Cauchy sequence iff $\lim _{n, m \rightarrow \infty} b_{d}\left(x_{n}, x_{n+p}\right)=0$ for all $p \in N^{*}$

Definition 2.8. A $b_{d}$-metric space $\left(X, b_{d}\right)$ is called complete if every $b_{d}$-Cauchy sequence in $X$ is $b_{d}$-convergent.

In general a $b_{d}$-metric is not continuous, as in Example 1.31 in [8] showed.

Example 2.9. Let $X=R^{+} \cup\{0\}$ and any constant $\alpha>0$. Define the function $d_{l}: X \times X \rightarrow[0, \infty)$ by $d_{l}(x, y)=\alpha(x+y)$. Then, the pair $\left(X, d_{l}\right)$ is a dislocated metric space.

Lemma 2.10. Let $\left(X, b_{d}\right)$ be a $b$-dislocated metric space with parameter $s \geq 1$. Suppose that $\left(x_{n}\right)$ and $\left(y_{n}\right)$ are $b_{d}$-convergent to $x, y \in X$, respectively. Then we have

$$
\frac{1}{s^{2}} b_{d}(x, y) \leq \lim _{n \rightarrow \infty} \inf b_{d}\left(x_{n}, y_{n}\right) \leq \lim _{n \rightarrow \infty} \sup b_{d}\left(x_{n}, y_{n}\right) \leq s^{2} b_{d}(x, y)
$$

In particular, if $b_{d}(x, y)=0$, then we have $\lim _{n \rightarrow \infty} b_{d}\left(x_{n}, y_{n}\right)=0=b_{d}(x, y)$. Moreover, for each $z \in X$, we have

$$
\frac{1}{s} b_{d}(x, z) \leq \lim _{n \rightarrow \infty} \inf b_{d}\left(x_{n}, z\right) \leq \lim _{n \rightarrow \infty} \sup b_{d}\left(x_{n}, z\right) \leq s b_{d}(x, z)
$$

In particular, if $b_{d}(x, z)=0$, then we have $\lim _{n \rightarrow \infty} b_{d}\left(x_{n}, z\right)=0=b_{d}(x, z)$.

Some examples in the literature shows that in general a $b$-dislocated metric is not continuous.

Example 2.11. If $X=R^{+} \cup\{0\}$, then $b_{d}(x, y)=(x+y)^{2}$ defines a $b$-dislocated metric on $X$ with parameter $s=2$.

\section{MAIN RESULT}

We consider the set $G_{4}$ of all continuous functions $g:[0, \infty)^{4} \rightarrow[0, \infty)$ with the following properties: 
a) $g$ is non-decreasing in respect to each variable

b) $g(t, t, t, t) \leq t, t \in[0, \infty)$

Some examples of these functions are as follows:

$$
\begin{aligned}
& g_{1}: g\left(t_{1}, t_{2}, t_{3}, t_{4}\right)=\max \left\{t_{1}, t_{2}, t_{3}, t_{4}\right\} \\
& g_{2}: g\left(t_{1}, t_{2}, t_{3}, t_{4}\right)=\max \left\{t_{1}+t_{2}, t_{2}+t_{3}, t_{1}+t_{3}, t_{3}+t_{4}\right\} \\
& g_{3}: g\left(t_{1}, t_{2}, t_{3}, t_{4}\right)=\left[\max \left\{t_{1} t_{2}, t_{2} t_{3}, t_{3} t_{1}, t_{3} t_{4}\right\}\right]^{\frac{1}{2}} \\
& g_{4}: g\left(t_{1}, t_{2}, t_{3}, t_{4}\right)=\left[\max \left\{t_{1}^{p}, t_{2}{ }^{p}, t_{3}{ }^{p}, t_{4}{ }^{p}\right\}\right]^{\frac{1}{p}}, p>0 .
\end{aligned}
$$

Theorem 3.1. Let $(X, d)$ be a complete $b$-dislocated metric space with parameter $s \geq 1$ and $T, S: X \rightarrow X$ two mappings satisfying the following contractive condition

$$
s d(S x, T y) \leq c g\left[d(x, y), d(x, S x), d(y, T y), \frac{d(x, S x) d(y, T y)}{1+d(x, y)}\right]
$$

for all $x, y \in X$ where $g \in G_{4}$ and $0 \leq c<1$. Then $T$ and $S$ have a unique common fixed point and if $u$ is a common fixed point of $S$ and $T$, then $d(u, u)=0$.

Proof. Let $x_{0}$ be an arbitrary point in $X$. Define the sequence $\left(x_{n}\right)$ as follows:

$$
x_{1}=S\left(x_{0}\right), x_{2}=T\left(x_{1}\right), \ldots, x_{2 n}=T\left(x_{2 n-1}\right), x_{2 n+1}=S\left(x_{2 n}\right), \ldots
$$

if we assume that for some $n \in N, x_{2 n+1}=x_{2 n}$ then $x_{2 n}=x_{2 n+1}=S x_{2 n}$ and also using the contractive condition of theorem we will have that $x_{2 n+1}=x_{2 n}$ is a fixed point of $T$. Thus we assume that for $n \in N, x_{2 n+1} \neq x_{2 n}$. By condition (1) we have:

$$
\begin{aligned}
& s d\left(x_{2 n+1}, x_{2 n+2}\right)=s d\left(S x_{2 n}, T x_{2 n+1}\right) \\
& \leq c g\left[d\left(x_{2 n}, x_{2 n+1}\right), d\left(x_{2 n}, S x_{2 n}\right), d\left(x_{2 n+1}, T x_{2 n+1}\right), \frac{d\left(x_{2 n}, S x_{2 n}\right) d\left(x_{2 n+1}, T x_{2 n+1}\right)}{1+d\left(x_{2 n}, x_{2 n+1}\right)}\right] \\
& \quad=\operatorname{cg}\left[d\left(x_{2 n}, x_{2 n+1}\right), d\left(x_{2 n}, x_{2 n+1}\right), d\left(x_{2 n+1}, x_{2 n+2}\right), \frac{d\left(x_{2 n}, x_{2 n+1}\right) d\left(x_{2 n+1}, x_{2 n+2}\right)}{1+d\left(x_{2 n}, x_{2 n+1}\right)}\right] \\
& \leq c d\left(x_{2 n+1}, x_{2 n}\right) .
\end{aligned}
$$

Thus

$$
d\left(x_{2 n+1}, x_{2 n+2}\right) \leq \frac{c}{s} d\left(x_{2 n}, x_{2 n+1}\right)
$$

Similarly by condition (1) have:

$$
\begin{aligned}
s d\left(x_{2 n}, x_{2 n+1}\right) & =\operatorname{sd}\left(T x_{2 n-1}, S x_{2 n}\right) \\
= & s d\left(S x_{2 n}, T x_{2 n-1}\right) \\
\leq & c g\left[d\left(x_{2 n}, x_{2 n-1}\right), d\left(x_{2 n}, S x_{2 n}\right), d\left(x_{2 n-1}, T x_{2 n-1}\right), \frac{d\left(x_{2 n}, S x_{2 n}\right) d\left(x_{2 n-1}, T x_{2 n-1}\right)}{1+d\left(x_{2 n}, x_{2 n-1}\right)}\right] \\
= & c g\left[d\left(x_{2 n}, x_{2 n-1}\right), d\left(x_{2 n}, x_{2 n+1}\right), d\left(x_{2 n-1}, x_{2 n}\right), \frac{d\left(x_{2 n}, x_{2 n+1}\right) d\left(x_{2 n-1}, x_{2 n}\right)}{1+d\left(x_{2 n}, x_{2 n-1}\right)}\right] \\
\leq & c d\left(x_{2 n-1}, x_{2 n}\right) .
\end{aligned}
$$

Thus

$$
d\left(x_{2 n}, x_{2 n+1}\right) \leq \frac{c}{s} d\left(x_{2 n-1}, x_{2 n}\right)
$$


Generally by conditions (2), (3) and denoting $k=\frac{c}{s}$, we have

$$
d\left(x_{2 n+1}, x_{2 n+2}\right) \leq k d\left(x_{2 n}, x_{2 n+1}\right) \leq \ldots \leq k^{2 n} d\left(x_{0}, x_{1}\right) \text { for } n \in \mathbb{N} .
$$

Since $0 \leq k<1$, taking limit for $n \rightarrow \infty$ we have

$$
d\left(x_{2 n+1}, x_{2 n+2}\right) \rightarrow 0 .
$$

Now, we prove that $\left(x_{n}\right)$ is a $b_{d}$-Cauchy sequence, and to do this let be $m, n>0$ with $m>n$, and using definition 2.4 (c) we have

$$
\begin{aligned}
b_{d}\left(x_{n}, x_{m}\right) & \leq s\left[b_{d}\left(x_{n}, x_{n+1}\right)+b_{d}\left(x_{n+1}, x_{m}\right)\right] \\
& \leq s b_{d}\left(x_{n}, x_{n+1}\right)+s^{2} b_{d}\left(x_{n+1}, x_{n+2}\right)+s^{3} b_{d}\left(x_{n+2}, x_{n+3}\right)+\ldots \\
& \leq s k^{n} b_{d}\left(x_{0}, x_{1}\right)+s^{2} k^{n+1} b_{d}\left(x_{0}, x_{1}\right)+s^{3} k^{n+2} b_{d}\left(x_{0}, x_{1}\right)+\ldots \\
& =s k^{n} b_{d}\left(x_{0}, x_{1}\right)\left[1+s k+(s k)^{2}+(s k)^{3}+\ldots .\right] \\
& \leq \frac{s k^{n}}{1-s k} b_{d}\left(x_{0}, x_{1}\right) .
\end{aligned}
$$

On taking limit for $n, m \rightarrow \infty$ we have $b_{d}\left(x_{n}, x_{m}\right) \rightarrow 0$ as $k s<1$. Therefore $\left(x_{n}\right)$ is a $b_{d}$-Cauchy sequence in complete b-dislocated metric space $\left(X, b_{d}\right)$. So there is some $u \in X$ such that $\left(x_{n}\right)$ dislocated converges to $u$. Therefore the subsequences $\left\{S x_{2 n}\right\} \rightarrow u$ and $\left\{T x_{2 n+1}\right\} \rightarrow u$. Since $T, S: X \rightarrow X$ are continuous mappings we get: $S u=u$ and $T u=u$. Thus, $u$ is a common fixed point of $T$ and $S$.

If consider that $T$ is continuous and $S$ not continuous we have that $T u=u$. Using the contractive condition of theorem we have,

$$
\begin{aligned}
s d\left(S u, T x_{2 n+1}\right) & \leq c g\left[d\left(u, x_{2 n+1}\right), d(u, S u), d\left(x_{2 n+1}, T x_{2 n+1}\right), \frac{d(u, S u) d\left(x_{2 n+1}, T x_{2 n+1}\right)}{1+d\left(u, x_{2 n+1}\right)}\right] \\
& \leq c g\left[d\left(u, x_{2 n+1}\right), d(u, S u), d\left(x_{2 n+1}, T x_{2 n+1}\right), \frac{d(u, S u) d\left(x_{2 n+1}, x_{2 n+2}\right)}{1+d\left(u, x_{2 n+1}\right)}\right] .
\end{aligned}
$$

Taking in upper limit as $n \rightarrow \infty$, using lemma 2.10, property of $g$ and result (4) we get

$$
s \frac{1}{s} d(u, S u) \leq c g[0, d(u, S u), 0,0] .
$$

This inequality implies $d(u, S u) \leq c d(u, S u)$ that means $d(u, S u)=0$. Thus $S u=u$ and $u$ is a fixed point of $S$.

If consider (c) we have that, $u$ is a common fixed point of $S$ and $T$. Using the contractive condition of theorem, we obtain

$$
\begin{aligned}
s d(u, u) & =s d(S u, T u) \\
& \leq c g\left[d(u, u), d(u, u), d(u, u), \frac{d(u, u) d(u, u)}{1+d(u, u)}\right] \\
& =c d(u, u) .
\end{aligned}
$$

The inequality above implies that $d(u, u) \leq k d(u, u)$. So $d(u, u)=0$, since $0 \leq k=\frac{c}{s}<1$

Uniqueness. Let suppose that $u$ and $v$ are two common fixed points of $T ; S$. From condition (1) we have: 


$$
\begin{aligned}
s d(u, v) & =s d(S u, T v) \\
& \leq c g\left[d(u, v), d(u, S u), d(v, T v), \frac{d(u, S u) d(v, T v)}{1+d(u, v)}\right] \\
& =c g\left[d(u, v), d(u, u), d(v, v), \frac{d(u, u) d(v, v)}{1+d(u, v)}\right] .
\end{aligned}
$$

Replacing $v=u$ in (5) we get:

$$
s d(u, u) \leq c g\left[d(u, u), d(u, u), d(u, u), \frac{d(u, u) d(u, u)}{1+d(u, u)}\right] \leq c d(u, u),
$$

i.e. $\quad d(u, u) \leq \frac{c}{s} d(u, u)=k d(u, u)$. Since $0 \leq k<1$ we obtain $d(u, u)=0$. Similarly replacing $u=v$ in (5), we obtain $d(v, v)=0$. Again from (5) have $d(u, v) \leq k d(u, v)$ since $0 \leq k<1$ get $d(u, v)=0$, which implies $u=v$. Thus fixed point is unique.

Corollary 3.2. Let $(X, d)$ be a complete $b$-dislocated metric space with parameter $s \geq 1$ and $T, S: X \rightarrow X$ two mappings satisfying the following contractive condition

$$
s d(S x, T y) \leq c g[d(x, y), d(x, S x), d(y, T y)]
$$

for all $x, y \in X$ where $g \in G_{3}$ and $0 \leq c<1$. Then $T$ and $S$ have a unique common fixed point and if $u$ is a common fixed point of $S$ and $T$, then $d(u, u)=0$.

Corollary 3.3. Let $(X, d)$ be a complete dislocated metric space and $T, S: X \rightarrow X$ two mappings satisfying the following contractive condition

$$
d(S x, T y) \leq c g\left[d(x, y), d(x, S x), d(y, T y), \frac{d(x, S x) d(y, T y)}{1+d(x, y)}\right],
$$

for all $x, y \in X$ where $g \in G_{4}$ and $0 \leq c<1$. Then $T$ and $S$ have a unique common fixed point and if $u$ is a common fixed point of $S$ and $T$, then $d(u, u)=0$.

The following example supports our theorem.

Example 3.4. Let $X=[0,1]$ and $d(x, y)=x+y$, for all $x, y \in X$. It is clear that $d$ is a dislocated metric on $X$. We define the self mappings $S, T: X \rightarrow X$ as follows

$$
S x=\left\{\begin{array}{ll}
\frac{1}{8} x, & x \in[0,1) \\
\frac{1}{6}, & x=1
\end{array} \text { and } T x= \begin{cases}\frac{1}{5} x, & x \in[0,1) \\
\frac{1}{3}, & x=1 .\end{cases}\right.
$$

Note that $S$ and $T$ are discontinuous maps. Now we will show that the contractive condition of 3.3 is satisfied for constant $c \in[0,1)$ and taking the function $g\left(t_{1}, t_{2}, t_{3}, t_{4}\right)=\max \left\{t_{1}, t_{2}, t_{3}, t_{4}\right\}$. We have the following cases:

Case 1. Note that for all $x, y \in[0,1)$, we have

$$
d(S x, T y)=d\left(\frac{x}{8}, \frac{y}{5}\right)=\frac{x}{8}+\frac{y}{5} \leq \frac{1}{5}(x+y)=\frac{1}{5} d(x, y)
$$

Case 2. Note that for $x=y=1$, we have 


$$
d(S x, T y)=d(S 1, T 1)=d\left(\frac{1}{6}, \frac{1}{3}\right)=\frac{1}{6}+\frac{1}{3}=\frac{1}{2}=\frac{1}{4} \cdot 2=\frac{1}{4} d(x, y) .
$$

Case 3. for $x \in[0,1)$ and $y=1$, we have

$$
d(S x, T y)=d\left(\frac{x}{8}, \frac{1}{3}\right)=\frac{x}{8}+\frac{1}{3} \leq \frac{1}{3}(x+1)=\frac{1}{3} d(x, y) .
$$

Case 4. For all $y \in[0,1)$ and $x=1$, we have

$$
d(S x, T y)=d\left(\frac{1}{6}, \frac{y}{5}\right)=\frac{1}{6}+\frac{y}{5}=\frac{5+6 y}{30} \leq \frac{1}{4}(1+y)=\frac{1}{4} d(x, y) .
$$

Thus all conditions of corollary 3.3 are satisfied and $x=0$ is a unique common fixed point of $S$ and $T$.

Also we note that this theorem is not available in a usual metric space if $d(x, y)=|x-y|$ and in $b$-metric space $d(x, y)=|x-y|^{2}$ because if consider points $x=y=1$ we will have

$$
\begin{gathered}
d(S 1, T 1)=\left|\frac{1}{6}-\frac{1}{3}\right|=\frac{1}{6}>c d(1,1)=0 \\
d(S 1, T 1)=\left|\frac{1}{6}-\frac{1}{3}\right|^{2}=\left(\frac{1}{6}\right)^{2}=\frac{1}{36}>c d(1,1)=0 .
\end{gathered}
$$

So the contractive condition is failed in two cases.

Corollary 3.5. Let $(X, d)$ be a complete dislocated metric space and $S: X \rightarrow X$ a selfmapping satisfying the following contractive condition

$$
d(S x, S y) \leq c g\left[d(x, y), d(x, S x), d(y, S y), \frac{d(x, S x) d(y, S y)}{1+d(x, y)}\right]
$$

for all $x, y \in X$ where $g \in G_{4}$ and $0 \leq c<1$. Then, $S$ has a unique fixed point and $d(u, u)=0$

Example 3.6. Let $X=[0,10]$ and $d(x, y)=\frac{1}{2}(x+y)$, for all $x, y \in X$. It is clear that $d$ is a dislocated metric on $X$ and $(X, d)$ is complete. Also $d$ is not a metric on $X$. We define the self-mapping $S: X \rightarrow X$ by

$$
S x=\left\{\begin{array}{l}
x-1, x \neq 0 \\
0 \quad, x=0
\end{array}\right.
$$

and take the function $g\left(t_{1}, t_{2}, t_{3}, t_{4}\right)=\max \left\{t_{1}, t_{2}, t_{3}, t_{4}\right\}$ and also choose the constant $c=\frac{9}{10}$. For $x, y \in\{0,1, \ldots, 10\}$, we have the following cases.

Case 1. For $x=y=0$ have $d(S x, S y)=d(0,0)=0$

Case 2. If $x=y>0$, then

$$
d(S x, S y)=d(x-1, x-1)=x-1 \leq \frac{9}{10} x=\frac{9}{10} d(x, y) .
$$

Case 3. If $x>y=0$, then

$$
d(S x, S y)=d(x-1,0)=\frac{1}{2}(x-1) \leq \frac{9}{10} \frac{x}{2}=\frac{9}{10} d(x, y) .
$$


Case 4. If $x>y>0$, then

$$
d(S x, S y)=d(x-1, y-1)=\frac{1}{2}(x+y-2) \leq \frac{9}{10} \frac{1}{2}(x+y)=\frac{9}{10} d(x, y) .
$$

Thus all conditions of theorem are satisfied and $S$ has a unique fixed point in $X$. Also we note that for $x=1$ and $y=10$ the contractive condition is failed in the usual metric.

Theorem 3.7. Let $(X, d)$ be a complete $b$-dislocated metric space and $T, S: X \rightarrow X$ two self-mappings satisfying the condition:

$$
\begin{aligned}
s d(S x, T y) \leq c \max & \{d(x, y)+d(x, S x), d(x, S x)+d(y, T y), \\
& \left.d(x, y)+d(y, T y), d(y, T y)+\frac{d(x, S x) d(y, T y)}{1+d(x, y)}\right\}
\end{aligned}
$$

for all $x, y \in X$ and $0 \leq 2 c<1$. Then $T$ and $S$ have a unique common fixed point in $X$.

Proof. This theorem is corollary of theorem 3.1 if we use the function $g_{2} \in G_{4}$.

Theorem 3.8. Let $(X, d)$ be a complete $b$-dislocated metric space and $T, S: X \rightarrow X$ two self mappings satisfying the condition:

$$
s^{p} d^{p}(S x, T y) \leq c \max \left\{d^{p}(x, y), d^{p}(x, S x), d^{p}(y, T y),\left(\frac{d(x, S x) d(y, T y)}{1+d(x, y)}\right)^{p}\right\},
$$

for all $x, y \in X$ and $0 \leq c<1$. Then $T$ and $S$ have a unique common fixed point in $X$.

Proof. This theorem is taken as a corollary of theorem 1, if we use the function $g_{4} \in G_{4}$.

Theorem 3.9. Let $(X, d)$ be a complete $b$-dislocated metric space and $T, S: X \rightarrow X$ two self-mappings satisfying the condition:

$$
s^{2} d^{2}(S x, T y) \leq c \max \left\{d(x, y) d(x, S x), d(x, S x) d(y, T y), d(x, y) d(y, T y), d(y, T y) \frac{d(x, S x) d(y, T y)}{1+d(x, y)}\right\}
$$

for all $x, y \in X$ and $0 \leq 2 c<1$. Then $T$ and $S$ have a unique common fixed point in $X$.

Proof. This theorem is corollary of theorem 1, if we use the function $g_{3} \in G_{4}$.

Remark 3.10. Results of the above theorems and corollaries are extended and unified of some classical fixed point results in metric spaces and generalization of results of the authors $[1,2,9,10,18,19]$ and other results in dislocated metric spaces.

\section{References}

[1] C. T. Aage, J. N. Salunke, The results on fixed points in dislocated and dislocated quasimetric space, Appl. Math. Sci.,2(59), (2008), 2941-2948.

[2] C. T. Aage, J. N. Salunke, Some results of fixed point theorem in dislocated quasi-metric spaces, Bulletin of Marathwada Mathematical Society, 9(2008),1-5 
[3] A. Beiranvand, S. Moradi, M. Omid, H. Pazandeh, Two fixed point theorems for special mapping, arXiv:0903.1504v1 [math.FA].

[4] I. A. Bakhtin, The contraction mapping principle in quasimetric spaces, Funct. Anal., Unianowsk Gos. Ped. Inst. 30, (1989), 26-37

[5] P. Hitzler, A. K. Seda, Dislocated topologies, J. Electr. Engin, 51(12/S):3:7, 2000.

[6] R. Shrivastava, Z. K. Ansari and M. Sharma, Some results on Fixed Points in Dislocated and Dislocated Quasi-Metric Spaces, Journal of Advanced Studies in Topology, Vol. 3, No.1, (2012)

[7] N. Hussain, J. R. Roshan, V. Parvaneh and M. Abbas, Common fixed point results for weak contractive mappings in ordered b-dislocated metric spaces with applications, Journal of inequalities and Applications, 1/486, (2013)

[8] M. A. Kutbi, M. Arshad, J. Ahmad, A. Azam, Generalized common fixed point results with applications, Abstract and Applied Analysis, volume 2014, article ID 363925, 7 pages

[9] K. Zoto, E. Hoxha, Fixed point theorems in dislocated and dislocated quasi-metric space, Journal of Advanced Studies in Topology; Vol. 3, No.1, (2012).

[10] Czerwik, S: Contraction mappings in b-metric spaces. Acta Math. Inform. Univ. Ostrav. 1, 5-11 (1993)

[11] L. B. Ciric, A generalization of Banach's contraction principle, Prooceedings of the American Mathematical Society, vol. 45, (1974), 267-273.

[12] K. M. Das, K. V. Naik, Common fixed point theorems for commuting maps on metric spaces. Proc Am Math Soc., 77, (1979), 369-373

[13] M. Arshad, A. Shoaib, I. Beg, Fixed point of a pair of contractive dominated mappings on a closed ball in an ordered dislocated metric space, Fixed point theory and applications, vol. 2013, article 115, 2013

[14] M. A. Alghmandi, N. Hussain, P. Salimi, Fixed point and coupled fixed point theorems on b-metric-like spaces, Journal of inequalities and applications, vol. 2013, article 402, 2013

[15] M. Arshad, A. Shoaib, P. Vetro; Common fixed points of a pair of Hardy Rogers type mappings on a closed ball in ordered dislocated metric spaces, Journal of function spaces and applications, vol 2013, article id 638181

[16] R. Yijie, L. Junlei, Y. Yanrong, Common fixed point theorems for nonlinear contractive mappings in dislocated metric spaces, Abstract and Applied Analysis vol 2013, article id 483059.

[17] K. Zoto, P. S. Kumari, E. Hoxha. Some Fixed Point Theorems and Cyclic Contractions in Dislocated and Dislocated Quasi-Metric Spaces, American Journal of Numerical Analysis, 2.3 (2014), 79-84.

[18] M. Kir, H. Kiziltunc, On Some Well Known Fixed Point Theorems in b-Metric Spaces, Turkish Journal of Analysis and Number Theory, 1.1 (2013), 13-16.

[19] M. P. Kumar, S. Sachdeva, S. K. Banerjee, Some Fixed Point Theorems in b-metric Space, Turkish Journal of Analysis and Number Theory 2.1 (2014), 19-22.

\footnotetext{
${ }^{1)}$ Faculty of Natural Sciences, University of Tirana, Tirana, Albania

${ }^{2)}$ Faculty of Natural Sciences, University of Gjirokastra, Gjirokastra, Albania

E-mail address: zotokastriot@yahoo.com

${ }^{3)}$ Department of Mathematics, K L University, Green Fields, A. P, India
} 